\title{
AVALIAÇÃO DA GERMINAÇÃO DE SEMENTES DE CAGAITA (EUGENIA DYSENTERICA DC) NATIVA DO CERRADO
}

\author{
CONCEIÇÃO APARECIDA PREVIERO, \\ LUCIVANIA DE SOUSA SANTOS, \\ ÍCARO GONÇALVES SANTOS, \\ PEDRO HENRIQUE CAMPELO.
}

\begin{abstract}
RESUMO - Estudos relacionados à desenvoltura de germinação e produção de espécies nativas são essenciais, uma vez que garantem a preservação delas, consequentemente alavancam as questões socioambientais e culturais das comunidades. A família Myrtaceae compreende uma diversidade de plantas arbustivas e arbóreas, dentre elas tem-se a espécie Eugenia Eugenia dysenterica DC, planta frutífera, nativa do Cerrado brasileiro, apreciada pela população, por se tratar de um fruto com potencial diverso. As sementes do fruto são recalcitrantes por apresentarem elevado grau de umidade (47\% a 53\%) e por perderem viabilidade entre $18 \%$ e $22 \%$ de umidade, desafiando seu tempo de armazenamento sem comprometer sua qualidade fisiológica. O objetivo deste trabalho foi avaliar a germinação das sementes de Eugenia dysenterica DC, em função de diferentes graus de umidade inicial, de modo a verificar seu comportamento. Conduziu-se o experimento no Laboratório de Sementes no CEULP/ULBRA. Os frutos foram coletados em novembro de 2011, em matrizes nos municípios de Palmas - TO e em Lajeado do Tocantins - TO. Determinou-se o grau de umidade das sementes pelo método de estufa a $\pm 105^{\circ} \mathrm{C}$, utilizando-se umidades iniciais de 65 a $20 \%$, com intervalo de $5 \%$. A viabilidade das sementes ocorreu pela semeadura em substrato de terra preta e areia, na proporção de 50\%. Para os parâmetros observados utilizou-se das análises de variância e as médias comparadas. Os resultados apresentaram desuniformidade quanto à germinação. $\mathrm{O}$ maior percentual de germinação foi observado em sementes semeadas a $60,55 \mathrm{e}$ $45 \%$ de umidade inicial. Nível letal foi apresentado quando semeadas com umidades inferiores a $25 \%$.
\end{abstract}

PALAVRAS-CHAVE - Cagaita; Umidade; Recalcitrante.

\section{INTRODUÇÃO}

Dentre as riquezas do bioma Cerrado encontram-se diferentes espécies florísticas que compõem sua vegetação, abrangendo diferentes territórios brasileiro como os estados de Goiás, Tocantins e no Distrito Federal, ou parte de outros estados, ocupando cerca de $25 \%$ de Cerrado [1]. Para Santos et al. [16], o Cerrado apresenta uma das diversidades mais ricas dentro da vegetação, com maior biodiversidade como savana do mundo. Entretanto, percebe-se que o cenário atual do Cerrado se mostra impactado pelo forte avanço das atividades antrópicas reduzindo sua cobertura vegetal.

Segundo Silva et al. [17], estudos apontaram que mais de $50 \%$ foram altamente modificadas, restando apenas $20 \%$ da formação original. Botelho Andrade [4] adverte que a modernização da agricultura e a expansão da pecuária alcançam o percentual de $80 \%$ dos prejuízos causados às florestas. Fatores como estes afetam a disposição da geração de espécies nativas, pois a manutenção do Cerrado compreende o desenvolvimento de uma semente, seguido por sua germinação e o desenvolvimento pós-germinativo através do crescimento da planta [6].

Para Walters et al. [18], as florestas constituem um reservatório da diversidade genética e exercem papel vital na manutenção da estabilidade do meio ambiente. Por isso, estudos relacionados à desenvoltura da germinação e produção de espécies nativas são essenciais para a questão conservacionista, que além de garantirem a preservação ecológica, promovem as questões socioambientais e culturais para as comunidades. As plantas nativas constituem importante patrimônio cultural e econômico para as populações locais, principalmente, quando a juventude inserida no meio adquire conhecimentos dessas plantas passados de gerações em gerações, valorizando suas raízes culturais e assegurando a continuidade do saber tradicional.

Para Nascimento Oliveira [13], o conhecimento leva à apreciação e ao uso racional, que, por sua vez, reduzirá a crescente ameaça à biodiversidade. Assim, as potencialidades dos recursos vegetais do Cerrado têm despertado o interesse 
mundial pelos frutos nativos do Brasil, se intensificando a cada ano, considerando que o Cerrado é um dos biomas brasileiros que mais contribuem para o fornecimento desses frutos.

A família Myrtaceae compreende uma diversidade de plantas arbustivas e arbóreas, dentre elas tem-se a espécie Eugenia dysenterica DC, do gênero Eugenia. É uma planta frutífera nativa do bioma Cerrado, conhecida popularmente como cagaita. $\mathrm{O}$ fruto tem propriedades laxantes, sendo bastante aproveitada para fins medicinais e apreciada na forma in natura. É uma planta decídua, heliófita, seletiva xerófita. Ocorre preferencialmente em formações primárias e em capoeiras de terrenos elevados, com solo argiloso ou arenoso bem drenados. A planta atinge altura aproximada de 4-8m, dotada de copa alongada e densa. Tronco tortuoso e cilíndrico, de $25-35 \mathrm{~cm}$ de diâmetro, com casca grossa, suberosa e profundamente sulcada nos sentidos vertical e horizontal. Com esta potencialidade podem ser utilizadas em sistemas de produção agrícola e que favorecem a exploração de populações nativas de forma sustentável [7], também sendo utilizados na medicina popular como antidiarreico e aproveitada na indústria de cortiça [12]. Na questão ecológica, seus frutos são fonte de alimento para animais silvestres, como por exemplo, para as aves, os roedores, os tatus, os canídeos, e entre outros [7].

Entretanto, as sementes características do Cerrado se apresentam em ortodoxas, intermediária e as recalcitrantes, sendo esta última, apresentando tamanhos relativamente grande e são caracterizadas por não sofrerem dessecação natural na planta - mãe ao longo do processo de maturação, sendo dispersas com elevados teores de água que, se reduzirmos a um nível considerado crítico, levarão à rápida perda da viabilidade e até à morte [8]. Em seu habitat, essas sementes são disseminadas com graus elevados de umidade, em meios úmidos ou durante a estação chuvosa [10]). Desta forma, as sementes da espécie Eugenia dysenterica DC se classificam dentro dos padrões de sementes recalcitrantes. Porém, alguns fatores da qualidade e condições das sementes são determinantes para eficiência da propagação da espécie. É importante considerar as interações dos ajustes metabólicos e estruturais, permitindo que as células resistem às perdas consideráveis de água sem que ocorra prejuízos acentuados [15].

Neste sentido, as formas de armazenamento das sementes de cagaita (Eugenia dysenterica DC) se tornam desafiantes considerando a manutenção das qualidades fisiológicas e de reprodução futura para a espécie. Assim, este trabalho teve como objetivo avaliar a germinação das sementes de $E$. dysenterica DC, em função de diferentes graus de umidade iniciais, de modo a verificar seu comportamento. O estudo foi realizado no Laboratório de Sementes, do Centro Universitário Luterano de Palmas (CEULP/ULBRA), de 2011 a 2012, em Palmas - Tocantins.

\section{MATERIAIS E MÉTODOS}

Foram coletados frutos maduros de cagaita (Eugenia dysenterica) nos municípios de Palmas - TO e em Lajeado -
Tocantins caídos no chão, nas coordenadas UTM 0825414 e 8869956; altitude de 220m, em novembro de 2011. Logo, o experimento foi conduzido no Laboratório de Sementes do Centro Universitário Luterano de Palmas (CEULP/ULBRA), no mês de novembro de 2011 a fevereiro de 2012. Anotou-se uma média de 71,6\% de umidade relativa (UR) do ar durante o ano, com valores maiores nos meses de janeiro a abril acima de $80 \%$ e valores inferiores nos meses de agosto, setembro e outubro - abaixo de $57 \%$ [3].

Os frutos foram lavados manualmente em água corrente para retirada da polpa para separação das sementes, utilizando peneiras. Após o processo de lavagem, distribuiu-se as sementes em bandejas com papel toalha para absorção do excesso de água. Em seguida, foram selecionadas e descartadas as sementes danificadas, com brocas e/ou com má formação. Separou-se as sementes em 10 amostras, com 100 sementes para conduzir o processo de desidratação.

Foram determinados o grau de Umidade Inicial (UI) das sementes e levados para desidratação em estufa a $105 \pm 3^{\circ} \mathrm{C}$ por 24 horas [5]. As sementes foram pesadas em cadinhos, com três repetições de $5 \mathrm{~g}$, em balança de precisão de $0,001 \mathrm{~g}$ modelo GEHAKA AG 200. Os resultados foram expressos em porcentagem com duas casas decimais. A determinação do grau de umidade baseia-se na perda de peso das sementes quando secas em estufa. A água contida nas sementes é expelida em forma de vapor pela aplicação do calor sob condições controladas, ao mesmo tempo em que são tomadas precauções para reduzir a oxidação, a decomposição ou a perda de outras substâncias voláteis durante as operações [5].

A desidratação intermitente das sementes foi realizada em estufa com circulação de ar a $40 \pm 3^{\circ} \mathrm{C}$, colocadas em bandejas de madeira, em camadas simples sem sobreposição e dispostas nas prateleiras da estufa. A umidade inicial das sementes foi de $68 \%$ em base úmida, foram estabelecidos 10 níveis de umidade para o plantio, de 65 a $20 \%$, com intervalo de $5 \%$. A pesagem das sementes foi em intervalos de 30 minutos para os níveis de umidade de 65 a $50 \%$ e de 60 minutos de 45 a $20 \%$. Durante o processo de desidratação as umidades foram aferidas pela perda de peso, uma vez que se conhecia a umidade inicial e a estabelecida (Figura 1).

As amostras que atingiram a umidade foram analisadas quanto ao grau de umidade e germinação. $\mathrm{O}$ substrato utilizado para germinação das sementes da cagaita foi a terra preta e areia, na proporção de $50 \%$. O substrato foi colocado em bandejas plásticas e semeadas 20 sementes por tratamento, com 3 repetições. $\mathrm{O}$ experimento foi conduzido em condições de ambiente natural, com temperatura e umidade relativa médias de $26,5^{\circ} \mathrm{C}$ e $87,4 \%$, respectivamente. Houve plantio nos dias 4, 5, 18, 24 e 28 de novembro de 2011.

A germinação iniciou-se no $11^{\circ}$ dia e ocorreu até o $60^{\circ}$ dia após a semeadura (Figura 2). Os resultados observados foram submetidos à análise de variância e teste de Tukey para a comparação de médias, ao nível de 5\% de probabilidade. Os dados quantitativos dos diferentes níveis de umidade inicial foram analisados por meio da regressão polinomial. 


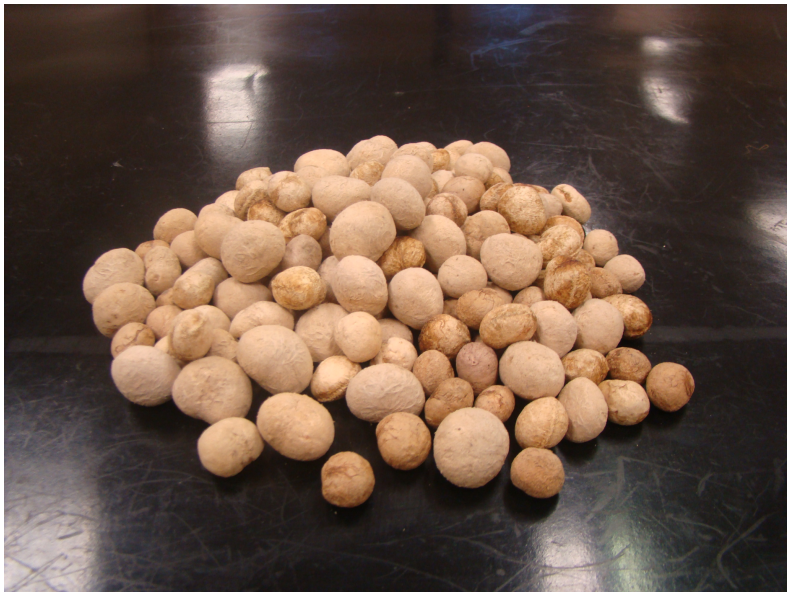

Figura 1. Sementes de cagaita (Eugenia dysenterica) desidratadas.

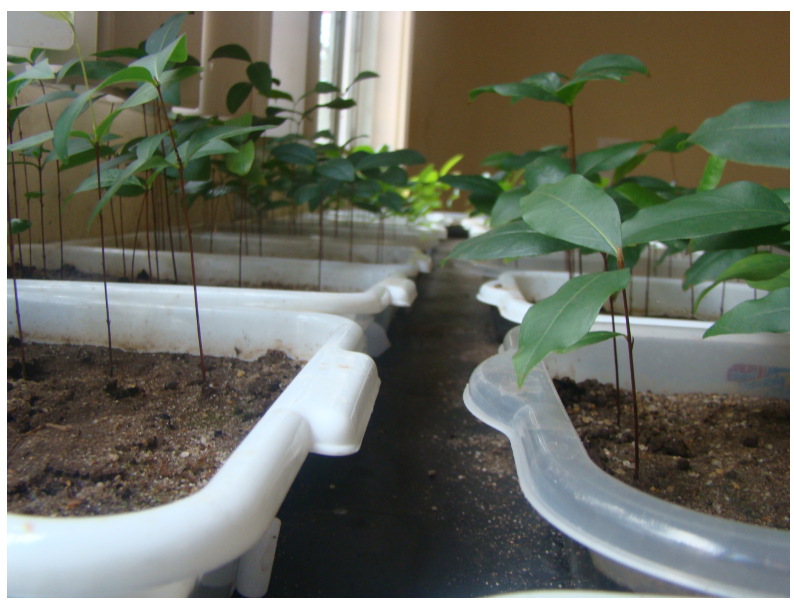

Figura 2. Plântulas de cagaita (Eugenia dysenterica) desidratadas.

\section{RESULTADOS E DISCUSSÃO}

Determinar níveis de desidratação tem o intuito de reduzir o teor de umidade inicial das sementes após a colheita, de modo a conhecer e preservar os atributos físicos e fisiológicos. As sementes úmidas são mais sensíveis a temperaturas elevadas, de modo que aquelas que apresentam maiores teores de água devem ser submetidas à desidratação a temperaturas baixas [14]. Há várias pesquisas indicando as temperaturas limites para secagem de sementes de cultivos agrícolas, mas poucas com relação às espécies nativas. A secagem é fundamental para o processo produtivo o qual demanda conhecimentos específicos para cada espécie, para que a qualidade das sementes não seja afetada.

$\mathrm{Na}$ secagem de sementes recalcitrantes, o maior cuidado é necessário quanto ao teor de umidade crítico e letal, que é variável, não existindo um teor de umidade padrão para secagem de sementes. O teor de umidade crítico aponta o início da perda de viabilidade. [2].

O teor de umidade inicial das sementes de cagaita foi de $68 \%$ em relação ao seu peso total. $\mathrm{O}$ aquecimento do ar de secagem a $40^{\circ} \mathrm{C}$ aumentou sua capacidade de absorção de água ocorrendo a desidratação das sementes nos níveis de umidade estabelecidos. A velocidade de perda de umidade da superfície da semente para o ambiente é maior do que o deslocamento de umidade do interior para sua superfície. [11]. Em função disso, o processo de secagem foi mais lento devido ao menor teor de umidade, conforme apresenta a Figura 3.

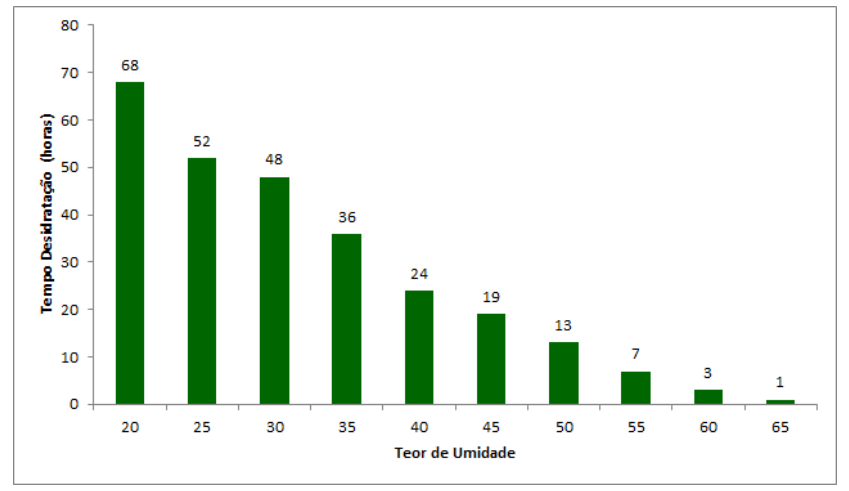

Figura 3. Tempo de desidratação das sementes de cagaita a temperatura de $40 \stackrel{\circ}{ } \mathrm{C}$.

Em geral, recomenda-se que a secagem de sementes seja realizada de tal forma que a temperatura delas não ultrapasse $40{ }^{\circ} \mathrm{C}$, para que não haja redução acentuada de sua qualidade fisiológica. As condições ambientais na cidade de Palmas - TO foram adequadas à germinação de sementes de cagaita, assim como aceleram a sua perda d'água, por se tratar de sementes recalcitrantes. Assim, a temperatura média de $26,5^{\circ} \mathrm{C}$ e a umidade relativa de $87,4 \%$ registradas no ambiente de condução do experimento estão dentro da classificação climática Köppen.

$\mathrm{Na}$ Figura 4 observa-se os efeitos significativos das umidades iniciais das sementes de cagaita no percentual de germinação, com 60, 55 e 45\% de umidade inicial apresentaram índice de germinação de $95 \%$. As sementes com 65 e $50 \%$ de umidade apresentaram cerca de $80 \%$ de germinação, enquanto as de 35 e $68 \%$ de umidade atingiram germinação inferior a $70 \%$. Índice de germinação abaixo (45\%) foi encontrado em sementes com $30 \%$ e $25 \%$ de umidade e a inviabilidade foi observada em sementes com umidades inferiores a $20 \%$. Diante disso, percebe-se desuniformidade quanto à germinação, ou seja, as sementes de um mesmo tratamento emergiram plântulas em tempos diversos. Devido a escassez de estudos referentes à germinação das sementes dessa espécie, e aliado às crescentes demandas pela propagação de espécies do cerrado são necessários maiores esclarecimentos quanto aos fatores que influenciam no processo germinativo.

A germinação ocorre em uma sequência de eventos fisiológicos influenciada por fatores externos (ambientais: luz, temperatura, disponibilidade de água e de oxigênio) e internos (inibidores e promotores da germinação) às sementes, que podem atuar por si ou em interação com os demais. [9].

Observa-se na Figura 5 que o $\mathrm{R}^{2}=0,94$ indica uma correlação significativa entre as variáveis independente (teor de umidade inicial) e dependente (germinação). As linhas 


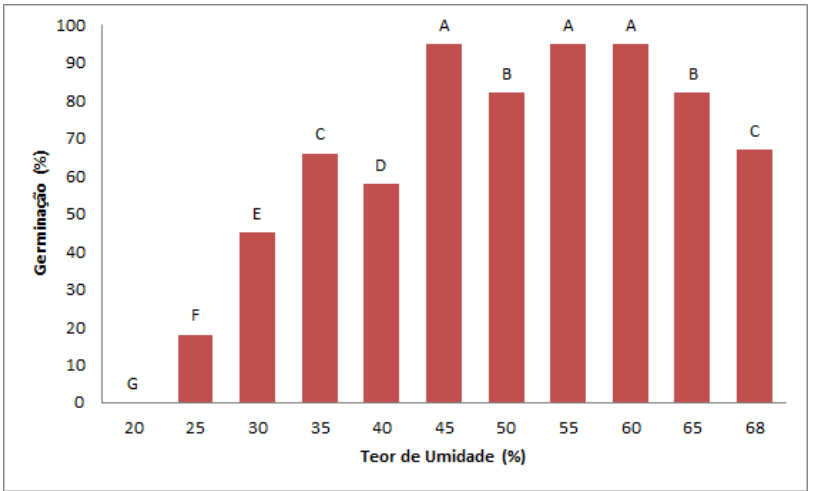

Figura 4. Percentual de germinação de sementes de cagaita em ambiente de laboratório.

curvas de uma equação polinomial são as mais adequadas para representar o desenvolvimento dos processos naturais.

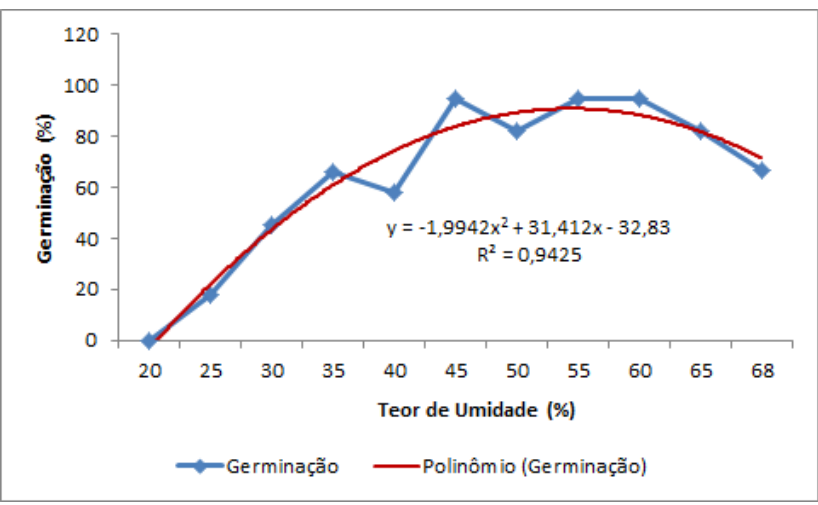

Figura 5. Ajuste de curva do percentual de germinação de sementes de cagaita em ambiente de laboratório.

\section{CONCLUSÃO}

Observou-se com esse estudo que sementes da espécie $E u$ genia dysenterica DC apresentam variações de germinação conforme o teor de umidade, sendo o maior percentual de germinação em sementes semeadas a 60,55 e $45 \%$ de umidade inicial. E o nível letal apresentado quando semeadas com umidades inferiores a $25 \%$.

\section{Referências}

[1] ÁVIDOS, M. F. D.; FERREIRA, L. T. Frutos dos Cerrados - Preservação gera muitos frutos. 2010. Disponível em: http://www.almanaquedocampo.com.br/imagens/files/frutos\%20do\%20 Cerrado.pdf. Acesso em: 01 de agosto de 2021.

[2] ANDRADE, A. C. S. et al. Conservação de sementes de cagaita (Eugenia dysenterica DC.). Myrtaceae. Informativo ABRATES, Brasília, v. 7, n. 1/2, p. 205, jul/ago. 1997.

[3] BARBOSA, D. C.; LIMA, M. B. Arquitetura bioclimática: Recomendação apropriada para Palmas - TO. In: CONGRESSO NORTE E NORDESTE DE PESQUISA E INOVAÇÃO, 6., 2010, Maceió. Anais Eletrônicos... Disponível em <http://connepi.ifal.edu.br>. Acesso em: 23 agosto de 2012.

[4] BOTELHO, A. C.; ANDRADE, M. P. A. expansão da silvicultura: impactos socioambientais em territórios camponeses no leste maranhense. In: XXI ENCONTRO NACIONAL DE GEOGRAFIA AGRÁRIA, 21, 2012, Uberlândia, MG. Territórios em Disputa: os desafios da Geografia Agrária nas contradições do desenvolvimento brasileiro. Uberlândia: UFU/LAGEA, 2012. p. 1 - 13. Disponível em: <http://www.lagea.ig.ufu.br/xx1enga/anais_enga_2012/eixos/999_1.pdf> Acesso em: 03 de maio de 2021.

[5] BRASIL. Ministério da Agricultura e Reforma Agrária. Regras para análise de sementes. Brasília: 2009. 365p.

[6] CASTRO, R.D. et al. 2004. Desenvolvimento de sementes e conteúdo de água. Disponível em:

$<$ https://www.researchgate.net/publication/40123992_Desenvolvimento_de_sementes_e_conteudo_de_agua_Seed_development_and_water_content>. Acesso em: 02 de maio de 2021.

[7] CAMILO, Y. M. V.. Seleção de plantas e caracterização de frutos de cagaiteiras (Eugenia dysenterica DC.). Goiânia: UFG, 2012. 96 p. Tese (Mestrado) - Programa de Pós-graduação em Agronomia, Universidade Federal de Goiás, 2012.

[8] COSTA, C. J. Armazenamento e conservação de sementes de espécies do Cerrado. Planaltina, DF: EMBRAPA Cerrados. 30 p, 2009.

[9] FLORIANO, E. P.. Germinação e dormência de sementes florestais, Caderno Didático n ${ }^{\circ} 2,1^{a}$ ed. il Santa Rosa, 2004. 19 p. il.

[10] FONSECA, S. C. L.; FREIRE, H. B. Sementes recalcitrantes: problemas pós-colheita. Bragantia [online]. 2003, vol.62, n.2, pp. 297-303. ISSN 1678-4499..

[11] LASSERAN, J. C. Princípios gerais de secagem. Revista Brasileira de Armazenamento. Viçosa, v.3, n.3, p.46, 1978.

[12] MACEDO, J. F. Plantas corticosas do Cerrado e sua utilização. Informe Agropecuário, Belo Horizonte, v. 15, n. 168, p. 33- 37, 1991.

[13] NASCIMENTO, M. S. B; OLIVEIRA, M. E. Diversidade e Uso de Plantas Nativas. EMBRAPA, 2005. Disponível em: $<$ http://www.embrapa.br/imprensa/artigos/2005/artigo.2005-1205.8820647706/.> Acesso em: 30 Maio 2013.

[14] NELLIST, M. E.; BRUCE, D. M. Drying and cereal quality. Aspects of Applied Biology, Warwick, v.15, p.439-456, 1987.

[15] NEVES, E. M. S. Secagem, Armazenamento e Condicionamento Osmótico de Sementes de Frutíferas Nativas do Cerrado. 2011. Dissertação (Mestrado em Agronomia) - Universidade Federal da Grande Dourados, Mato Grosso do Sul, 2011.

[16] SANTOS, B. R. et al.. 2007. Pequizeiro (Caryocar brasiliense Camb.): Uma espécie promissora do Cerrado brasileiro. Disponível em: <http://www.editora.ufla.br/Boletim/pdf/bol_64.pdf >. Acesso em: 20 Maio 2013.

[17] SILVA, L.O.et al. Levantamento florístico e fitossociológico em duas áreas de Cerrado sensu stricto no Parque Estadual da Serra de Caldas Novas, Goiás. Acta Botânica Brasílica, v. 16, n.1, p.43-52, São Paulo-SP, 2002. Disponível em: <https://www.scielo.br/pdf/abb/v16n1/9460.pdf>. Acesso em: 01 Maio 2021.

[18] WALTERS, C.et al. Genebanks in the post-genomic age: emerging roles and anticipated uses. Biodiversity: 2008. 9: 68-71.

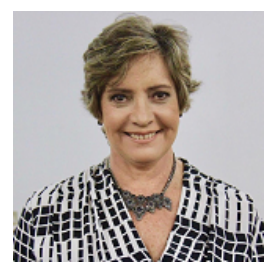

\section{CONCEIÇÃO APARECIDA PREVIERO}

Professora titular no Centro Universitário Luterano de Palmas, Tocantins. Graduada em Biologia pela Universidade de Bauru. Mestrado e Doutorado em Engenharia Agrícola, pela Universidade Estadual de Campinas - UNICAMP. Coordenadora do Núcleo de Estudos em Agroecologia Unitas Agroceológica. Atua especificamente no resgate, multiplicação e doação de sementes crioulas; produção de mudas de espécies nativas; pós-colheita de deterioráveis e perecíveis, gestão da qualidade na agricultura; produção agrícola sustentável; agricultura regenerativa, agroecologia e educação ambiental. Tem projetos de Pesquisa, Inovação Tecnológica e Extensão junto a Agricultura Familiar e Comunidades Tradicionais. 


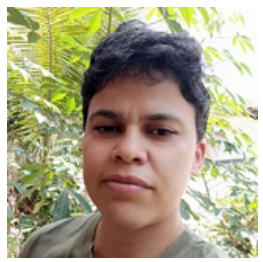

\section{LUCIVANIA DE SOUSA SANTOS}

Graduada em Ciências Biológicas pelo Centro Universitário Luterano de Palmas (CEULP/ULBRA),

em 2014. Tem atuação na Iniciação Científica com Plantas Medicinais, germinação de sementes nativas e crioulas, experiência em áreas temáticas da Agroecologia e Produção Orgânica em cenário de prática, bem como atuação em atividades de Educação Ambiental pelo NEA- Unitas Agroecológica, do CEULP/ULBRA. Possui Formação Inicial Continuada como Produtor Agropecuário no âmbito do Programa Novos Caminhos, pelo Instituto Federal do Tocantins - IFTO (2020). Atualmente é residente no Programa Multiprofissional em Saúde Coletiva pela Fundação Escola de Saúde Pública de Palmas (FESP), na categoria profissional Bióloga.

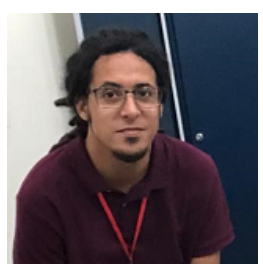

ÍCARO GONÇALVES SANTOS

Tecnólogo em Gestão Ambiental (UniCatólica, 2009) Biólogo (CEULP/ULBRA,2014), Mestre em Ciências Florestais e Ambientais (UFT, 2017), Especialista em Saúde Coletiva (COREMU/FESP, 2020).

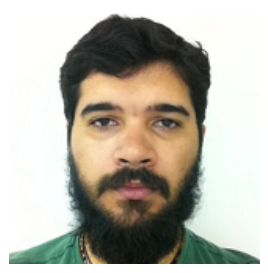

\section{PEDRO HENRIQUE CAMPELO}

Biólogo pelo Centro Universitário Luterano de Palmas, mestre em Ecologia de Ecótonos pela Universidade Federal do Tocantins e Doutorando pela Universidade de Brasília, com previsão de conclusão em agosto de 2021. Tem interesse no estudo da ecologia e agroecologia, bem como em suas diferentes subdivisões, principalmente no que diz respeito à ecofisiologia vegetal (germinação de sementes) e animal de espécies endêmicas do Cerrado. 